\title{
Asian-White disparities in short sleep duration by industry of employment and occupation in the US: a cross-sectional study
}

\author{
Chandra L Jackson ${ }^{1 *}$, Ichiro Kawachi ${ }^{2}$, Susan Redline ${ }^{3}$, Hee-Soon Juon ${ }^{4}$ and Frank B Hü ${ }^{1,2}$
}

\begin{abstract}
Background: Although short sleep is associated with an increased risk of morbidity as well as mortality and has been shown to vary by industry of employment and occupation, little is known about the relationship between work and sleep among Asian Americans.

Methods: Using a nationally representative sample of US adults $(n=125,610)$ in the National Health Interview Survey from 2004-2011, we estimated prevalence ratios for self-reported short sleep duration ( $<7$ hours) in Asians compared to Whites by industry of employment and occupation using adjusted Poisson regression models with robust variance.

Results: Asians were more likely to report short sleep duration than Whites (33 vs. 28\%, $p<0.001$ ), and the AsianWhite disparity was widest in finance/information and healthcare industries. Compared to Whites after adjustments, short sleep was also more prevalent among Asians employed in Public administration (PR $=1.35$ [95\% Cl: 1.17,1.56]), Education ( $\mathrm{PR}=1.29$ [95\% Cl: 1.08,1.53]), and Professional/Management ( $\mathrm{PR}=1.18$ [95\% Cl: 1.03,1.36]). Short sleep, however, was lower among Asians in Accommodation/Food ( $P R=0.81$ [95\% Cl: 0.66, 0.99]) with no difference in Retail. In professional and support-service occupations, short sleep was higher among Asians, but was not different among laborers.
\end{abstract}

Conclusions: U.S. Asian-White disparities in short sleep varied by industries, suggesting a need to consider both race and occupational characteristics to identify high-risk individuals.

Keywords: Sleep, Work, Industry, Occupation, Asian, Race

\section{Background}

Insufficient sleep ( $<7$ hours/day) has been shown to increase risk of weight gain and obesity, hypertension, diabetes, coronary heart disease and subsequent mortality [1-11]. Among Asian populations in the US and abroad, short sleep is independently associated with insulin resistance [12] and an increased risk of diabetes [13]. In 2008, Asian Americans had a higher age-adjusted prevalence of diabetes (8.2\%) than Whites (7.0\%) [14], and for any given weight, they also appear to have a higher risk of obstructive sleep apnea compared to Whites [15]. In a meta-analysis of prospective studies of sleep duration

\footnotetext{
* Correspondence: cjackson@hsph.harvard.edu

'Department of Nutrition, Building II, Room 302, Harvard School of Public

Health, 655 Huntington Avenue, Boston, MA, USA

Full list of author information is available at the end of the article
}

and mortality, both short and long sleep in East Asian countries (Japan, Taiwan) were more strongly associated with mortality compared to studies conducted in Europe and the US [16]. In a nationally representative sample of the US, Asians, however, reported the least sleep complaints compared to Latinos, Blacks and Whites in a study that found lower socioeconomic status (SES) was associated with higher sleep complaints [17]. While Asian Americans tend to have high educational attainment and to be well represented in professional occupations with relatively high incomes, there may also be important variation in short sleep by occupation within the Asian population and in comparison to Whites.

Short sleep duration has been shown to vary by industry and occupation among US workers with certain industries (e.g. transportation, manufacturing, public administration) 
well above the median and several (e.g. education, agriculture) well below. $[18,19]$. There, however, have been limited race-specific investigations of sleep by industry of employment and occupation although important racial/ ethnic differences in influential factors are likely to exist. For instance, one's race/ethnicity as well as occupation likely plays an important role in producing psychosocial stress and job strain that negatively impacts health through, for example, discrimination or limited control over job demands/prestige as illustrated by the Karasek and Theorell demand-control model [20-22]. In a previous study, we found that the prevalence of short sleep increased as professional responsibility increased among Blacks while the prevalence decreased among their White counterparts [23]. We concluded that Black-White disparities in sleep duration by industry and occupation may reflect racial differences in work schedules as well as stressors and stress associated with specific jobs. In particular, Blacks are more likely to engage in shift work (especially night shifts) with non-standard work schedules and to work multiple low-wage jobs [24,25]. Blacks are also more likely to have long work hours, report job stress related to discrimination, and to work in low control/high demand positions with low decision-making power. Among professional workers, Blacks, may have more limited networks to provide supportive resources, compared to Whites, and may develop an extraordinarily high work ethic that could damage health through inadequate sleep as a coping strategy to overcome negative racial stereotypes/stressors [26-28].

The impact of industries of employment and occupations on sleep among Asian Americans as well as how they may be affected differently than Whites and Blacks is important to identify and understand to create effective, tailored interventions to improve sleep for optimal health and productivity in this population. However, very few studies have investigated Asian-White disparities in the work-sleep relationship that may occur due to differences in, for example, SES, work ethic and drive to succeed, social support, cultural factors like religion, and acculturation. Therefore, we sought to examine racial/ ethnic disparities in short sleep duration by industry of employment and occupation using a nationally representative sample of US Asian and White adults reporting short sleep in the National Health Interview Survey from 2004 to 2011.

\section{Methods}

\section{The National Health Interview Survey}

We analyzed data from the National Health Interview Survey (NHIS), which is a series of cross-sectional, nationally representative surveys that use a three-stage stratified cluster probability sampling design to conduct in-person interviews in the households of non-institutionalized US civilians. A detailed description of NHIS procedures has been previously published [29]. In short, an annual probability sample of households was interviewed by trained interviewers from the US Census Bureau on a continuous basis throughout the year to obtain information about health and other characteristics of each member of the sampled household. The data were collected using computer-assisted personal interviewing (CAPI). A randomly selected adult and child (not used in this analysis) provided more extensive health-related information, and the final response rate for sample adults was 67\% (range: 61-72\%). Our study was approved by the Harvard School of Public Health's Institutional Review Board, and the NHIS received informed consent from each study participant.

\section{Study participants}

Non-Hispanic White and Non-Hispanic Asian (hereafter, White and Asian) adults aged $\geq 18$ years were included in our study. Participants were excluded from the study analysis if they had missing data on sleep, industry and employment status, were deemed unemployed or not in the labor force, or had an extreme body-mass index (BMI) - i.e. either $<15$ or $>70 \mathrm{~kg} / \mathrm{m}^{2}$. Although previous studies suggest sleep patterns among immigrants may differ from individuals born in the US [30], we included non-US born participants for evaluation and robust sample size (particularly, among the Asian participants). As NHIS is not designed to provide accurate estimates of military persons, participants in armed forces were excluded. Our final sample consisted of 125,610 adults.

\section{Variable measurements}

\section{Sleep duration}

Participants reported the average hours of sleep they usually get in a 24-hour period. Interviewers were trained to report hours of sleep in whole numbers, rounding values of 30 minutes or more up to the nearest hour or otherwise rounding down. Short sleep duration was defined as usual sleep duration of $<7$ hours, and adequate sleep was categorized as 7 hours of sleep. Seven hours of sleep was used as the reference because it has been shown to be associated with the lowest levels of morbidity and mortality $[7,11,31]$, and our sample size could provide stable estimates. We are comparing short and adequate sleepers only, and do not note differences among longer sleepers as the causes (e.g. depression, poor health status, low socioeconomic status) have been shown to fundamentally differ from short sleep and the potential mechanisms linking long sleep to poor health outcomes are considered more speculative.

\section{Race/ethnicity}

Race/ethnicity was based on self-identification. Participants were asked, 'What race or races do you consider 
yourself to be?", They then selected 1 or more of the following categories: White, Black/African American, Asian, American Indian/Alaskan native or multiple race. The Asian category consists of 'Filipino' (24\%), 'Chinese' (20\%), 'Asian Indian' (20\%), and 'Other Asian' (36\%); sample size precluded us from further stratifying them by specific ethnic groups. We focus on Asian-White disparities in sleep duration because the underlying biological and social mechanisms are likely to further vary for other races/ethnicities. We have previously reported on BlackWhite disparities, and Whites are used as the comparison group for statistical stability and because this group represents the majority population in this country.

\section{Industry of employment}

For employed sample adults, the North American Industrial Classification System (NAICS) Codes were categorized into the following 8 industry categories: 1) 'Construction'; 'Manufacturing'; 'Agriculture, Forestry, Fishing, and Hunting'; 'Mining'; 'Utilities'; and 'Wholesale Trade'; and 'Transportation and Warehousing', 2) 'Retail Trade', 3) 'Information'; 'Finance and Insurance'; and 'Real Estate and Rental and Leasing', 4) 'Professional, Scientific, and Technical Services'; 'Management of Companies and Enterprises'; and 'Administrative and Support and Waste Management and Remediation', 5) 'Education Services', 6) 'Health Care and Social Assistance', 7) 'Accommodation and Food Services' as well as 8) 'Other Services (except Public Administration)'; 'Public Administration'; and 'Arts, Entertainment, and Recreation'.

\section{Occupation}

Adults who were either working at a paying or nonpaying job during the week prior to the survey, who had a job or business but were not at work during the prior week, or who ever worked were asked about their occupation, which was categorized based on the Standard Occupational Classification System. Based on type of work, we combined occupation categories into 'Professional/management', 'Support Services' and 'Laborers'.

\section{Covariates}

Educational attainment was categorized as less than high school (<HS) (no high school diploma), high school (HS) (high school or general equivalency diploma), and greater than high school (>HS) (education beyond high school). Household income was dichotomized at above and below $\$ 35,000$, and poverty status was based on being below the poverty line after the participants' best estimate of total income of all family members from all sources before taxes. Employment status was based on the week prior to the interview for all adults, and was categorized as 'working for pay', 'working without pay', 'job not at work', 'unemployed', and 'not in the labor force.' Class of work (based on current, longest held, or most recently held job or work situation) was classified as either 1) an employee of a private company, business, or individual for wages, salary, or commission; 2) a federal, state, or local government employee; 3) self-employed in OWN business, professional practice or farm; 4) or working without pay in a family-owned business or farm.

Height and weight, based on self-report, were used to calculate body mass index (BMI) by dividing measured weight in kilograms by height in meters squared. In Whites, obesity was defined as BMI $\geq 30 \mathrm{~kg} / \mathrm{m}^{2}$, overweight as $25.0-29.9 \mathrm{~kg} / \mathrm{m}^{2}$, normal weight as $18.5-$ $24.9 \mathrm{~kg} / \mathrm{m}^{2}$, and underweight as $\mathrm{BMI}<18.5 \mathrm{~kg} / \mathrm{m}^{2}$. In Asians, obesity was defined as BMI $\geq 27.5 \mathrm{~kg} / \mathrm{m}^{2}$, overweight as $23.0-27.4 \mathrm{~kg} / \mathrm{m}^{2}$, normal weight as $18.5-$ $22.9 \mathrm{~kg} / \mathrm{m}^{2}$, and underweight as BMI $<18.5 \mathrm{~kg} / \mathrm{m}^{2}$ [32]. Marital status was classified as married/living with partner, divorced/separated/widowed, or never married, and both smoking status and lifetime alcohol consumption was categorized as 'never', 'current', or 'former'. Leisuretime physical activity was categorized as 'never/unable', 'low', or 'high'. Participants reporting 'never' or 'unable to do this type activity' were categorized as 'none', and those engaging in at least some level of activity and providing a specific number of activity bouts were dichotomized at the midpoint of these bouts and labeled as 'low' or 'high'. In terms of medical conditions, adults reported if they had ever been told by a doctor or other health professional that they had "hypertension, also called high blood pressure" or, separately, if they had "diabetes or sugar diabetes". Participants were also asked if a doctor or other health professional ever diagnosed them as having any kind of heart condition or disease other than coronary heart disease, angina pectoris, or a myocardial infarction as well as if a doctor or other health professional ever diagnosed them as having coronary heart disease. These variables were combined to adjust for heart disease. Residential regions of the country were categorized as the South, Midwest, Northeast, and West, and participant self-reported general health status was considered excellent/very good, good, or fair/poor.

\section{Statistical analysis}

We pooled NHIS data across 8 survey years (2004-2011), which was merged by the Integrated Health Interview Series [33]. Sampling weights that account for the unequal probabilities of selection resulting from the sample design, non-response, and oversampling of certain subgroups were employed in all analyses, and Taylor series linearization was used to calculate standard errors for variance estimation [34]. The STATA "subpop" command was used for correct variance estimation of estimates, and different sampling designs in 1997 to 2005 versus 2006 to 2008 were accounted for by the Integrated Health Interview Series. 
Rao-Scott Second-order corrected Pearson statistics take survey weights into account for contingency table chisquare tests [35]. Continuous variables were presented as means \pm standard errors (SE), and categorical variables as absolute values with percentages. We used STATA statistical software version 12 (STATA Corporation, College Station, Texas, USA, 2007) [36].

We used Poisson regression models with a robust variance estimator to directly estimate prevalence ratios with corresponding 95\% confidence intervals for short sleep duration in Asians compared to short sleep in Whites by industry of employment and, separately, for occupation [37]. Demographic, health behavior, socioeconomic, and clinical characteristics were pre-specified and entered into the model as groups in a stepwise manner. For greater statistical stability for the Asian-White comparisons, Whites were used as the reference categories because they had the largest sample size. For models stratified for Asians and Whites, we adjusted first for age in 3 categories $(18-49,50-64,65+$ years), and then for demographic factors such as sex, marital status, and educational attainment. Subsequently, we adjusted for health behaviors including smoking status, alcohol consumption, and leisure-time physical activity and then, in a separate model, we adjusted for self-reported health status, hypertension, diabetes, heart disease, cancer and 4 standard BMI categories. Living in poverty, household income above or below $\$ 35,000$, classes of occupation as well as occupation (when investigating industry differences) were all accounted for in the final model. We used Rao-Scott second-order corrected Pearson statistics again for each industry to test for race-specific temporal trends in short sleep duration over the study period by industry of employment. In addition to testing racial disparities in short sleep duration for each survey period, differences in linear trends in short sleep from 2004 to 2011 between Asians and Whites within each industry category were formally tested using multivariable-adjusted linear regression models where survey year was treated as a dummy variable. In a subsidiary analysis, we investigated differences in short sleep prevalence by immigrant status.

\section{Results}

\section{Study population}

Our sample consisted of 125,610 (8,390 Asian; 117,220 White) participants. Their mean age was $51 \pm 11$ years, 51\% were men, 5\% were Asian, 32\% (31 for Whites; 53 for Asians) had at least a college education. Among all participants, 35,961 (28\%) were considered short sleepers (<7 hours), 40,409 (33\%) adequate sleepers (7 hours), and 49,240 (39\%) reported sleeping more than 7 hours. Table 1 shows weighted estimates of age-adjusted prevalence of short sleep by sociodemographic, health behavior and clinical factors among Asian and White participants.
Asians were more likely to report short sleep than Whites (31 vs. $28 \%, \mathrm{p}<0.001$ ). For education, the greatest prevalence of short sleep was among high school graduates (36\%) in Whites and in individuals with some college for Asians (36\%). Short sleep prevalence in individuals living in poverty was similar for both Asians and Whites (35 vs. $37 \%)$. The overall percentage point difference in short sleep between Asians and Whites was 3\%, 6\% for professional/management positions, $6 \%$ for support services and $2 \%$ for laborers. Additional file 1: Table S1 shows the distribution of the aforementioned characteristics among participants with short sleep. Although the sample size was too low to stratify all analyses by Asian subgroup, the overall prevalence of short sleep duration varied by Asian subgroup with Chinese (prevalence $(p)=23.6 \% \quad[95 \%$ CI: 21.0-26.4]) and Asian Indians ( $\mathrm{p}=24.8 \%$ [95\% CI: 21.9-27.9]) having a significantly lower prevalence than Filipinos ( $\mathrm{p}=37.4 \%$ [95\% CI: 34.7-40.1]) and Other Asians ( $\mathrm{p}=33.1 \%$ [95\% CI: 31.0-35.2]).

\section{Asian-White differences in sleep duration by industry and occupation}

Table 2 shows adjusted prevalence ratios of short sleep duration for Asians and Whites by industry of employment. Compared to Whites, adjusted short sleep was more prevalent in Asians employed in the following industries: Finances/Information/Real estate (prevalence ratio $(\mathrm{PR})=1.46$ [95\% confidence interval $(\mathrm{CI}): 1.26,1.69]$ ), Health care and social services $(\mathrm{PR}=1.39$ [95\% CI: $1.22,1.57])$, Public administration/Other services ( $P R=$ 1.35 [95\% CI: 1.17,1.56]), Education (PR $=1.29$ [95\% CI: 1.08,1.53]), Professional/Administrative/Management $(\mathrm{PR}=1.18$ [95\% CI: 1.03,1.36]), and Manufacturing/Construction $(\mathrm{PR}=1.14 \quad[95 \% \mathrm{CI}: 1.03,1.26])$. Short sleep prevalence, however, was lower among Asians compared to Whites in the Accommodation and food services industry $(\mathrm{PR}=0.81$ [95\% CI: 0.66, 0.99]). There was no observed difference between Asians and Whites in Retail $(\mathrm{PR}=1.05$ [95\% CI: 0.87, 1.26]).

Adjusted prevalence ratios of short sleep duration for Asians compared to Whites by occupation are provided in Table 3. The prevalence of short sleep among Asians was higher among professional (PR: 1.25 (95\% CI: 1.141.38 ) and management (PR: 1.28 (95\% CI: 1.18-1.38) workers, and short sleep was not different among laborers (PR: 1.07 (95\% CI: 0.97-1.18). Although limited by sample size, US-born Asians in professional occupations (PR: 1.56 (95\% CI: 1.33-1.83) had a higher short sleep prevalence than Whites while non-US born Asians did not (see Additional file 2: Table S2).

\section{Trends in sleep duration by industry}

Figure 1 illustrates temporal trends in the age-adjusted prevalence of short sleep duration by industry of 
Table 1 Age-adjusted prevalence of short sleep duration by sociodemographic, health behavior and clinical characteristics among 125,610 US Asian and White participants, 2004-2011

\begin{tabular}{|c|c|c|c|c|c|c|}
\hline & \multicolumn{6}{|c|}{ Short sleep duration ( $<7$ hours) } \\
\hline & White (n) & White (\%) & Asian*(n) & Asian (\%) & Total (n) & Total (\%) \\
\hline & & $95 \% \mathrm{Cl}$ & & $95 \% \mathrm{Cl}$ & & $95 \% \mathrm{Cl}$ \\
\hline Sample size, short sleepers & 33,354 & $28(27.8-28.5)$ & 2,607 & $33(31.0-34.1)$ & 35,961 & $28(27.9-28.6)$ \\
\hline \multicolumn{7}{|l|}{ Age group, (\%) } \\
\hline $18-49$ & 18,172 & $31(30.6-31.6)$ & 1,611 & $29(27.5-31.0)$ & 19,783 & $31(30.5-31.5)$ \\
\hline $50-64$ & 9,346 & $29(28.7-29.9)$ & 637 & $36(33.2-39.4)$ & 9,983 & $30(29.0-30.2)$ \\
\hline$\geq 65$ & 5,836 & $21(20.6-21.7)$ & 359 & $32(28.7-35.3)$ & 6,195 & $22(20.9-22.1)$ \\
\hline Women & 16,041 & $28(27.9-28.8)$ & 1,315 & $32(30.2-34.4)$ & 18,605 & $28(28.0-28.9)$ \\
\hline Men & 17,313 & $28(27.3-28.3)$ & 1,292 & $33(30.7-34.8)$ & 17,356 & $28(27.5-28.4)$ \\
\hline \multicolumn{7}{|l|}{ Educational attainment } \\
\hline$<$ High school & 10,418 & $31(30.0-31.3)$ & 459 & $32(28.5-35.1)$ & 10,877 & $31(30.0-31.2)$ \\
\hline High school graduate & 3,303 & $36(34.3-36.8)$ & 202 & $32(27.6-36.8)$ & 3,505 & $35(34.0-36.5)$ \\
\hline Some college & 11,145 & $30(29.1-30.4)$ & 651 & $36(32.4-38.6)$ & 11,796 & $30(29.3-30.5)$ \\
\hline$\geq$ College & 8,488 & $23(22.1-23.2)$ & 1,295 & $32(29.5-33.9)$ & 9,783 & $23(22.7-23.8)$ \\
\hline \multicolumn{7}{|l|}{ Marital status } \\
\hline Married & 15,624 & $26(25.8-26.7)$ & 1,416 & $32(29.8-33.5)$ & 17,040 & $27(26.1-27.0)$ \\
\hline Divorced/separated/widowed & 10,868 & $35(34.4-35.8)$ & 479 & $37(33.9-40.5)$ & 11,347 & $35(34.4-35.8)$ \\
\hline Never married & 6,791 & $28(26.6-28.6)$ & 708 & $34(29.3-37.9)$ & 7,499 & $28(26.8-28.8)$ \\
\hline Non-US born & 1,400 & $27(25.8-28.8)$ & 1,873 & $31(29.5-32.7)$ & 3,273 & $29(27.7-29.8)$ \\
\hline Living in poverty & 3,526 & $37(35.5-38.3)$ & 297 & $35(29.9-40.3)$ & 3,823 & $37(35.4-38.1)$ \\
\hline Household income $<\$ 35,000$ & 18,223 & $27(26.1-27.0)$ & 1,570 & $32(30.5-34.4)$ & 19,793 & $27(26.4-27.2)$ \\
\hline \multicolumn{7}{|l|}{ Class of worker } \\
\hline Private wage & 24,910 & $29(28.7-29.6)$ & 1,989 & $33(31.3-35.1)$ & 26,899 & $29(28.8-29.7)$ \\
\hline Government & 5,286 & $26(25.3-26.9)$ & 396 & $31(26.7-35.5)$ & 5,682 & $26(25.5-27.1)$ \\
\hline Self employed & 2,970 & $25(24.1-26.0)$ & 200 & $29(24.9-33.7)$ & 3,170 & $25(24.2-26.2)$ \\
\hline \multicolumn{7}{|l|}{ Occupation } \\
\hline Professional/management & 6,345 & $25(24.6-26.1)$ & 705 & $31(27.7-33.9)$ & 7,050 & $26(24.9-26.3)$ \\
\hline Support services & 14,848 & $27(26.0-27.0)$ & 1,196 & $33(30.7-34.9)$ & 16,044 & $27(26.3-27.3)$ \\
\hline Laborers & 12,034 & $32(31.7-33.0)$ & 689 & $34(31.1-36.4)$ & 12,723 & $32(31.8-33.0)$ \\
\hline \multicolumn{7}{|c|}{ Occupation [work hours ( $\geq \mathbf{4 0}$ hours/wk)] } \\
\hline Professional/management & 4,234 & $27(25.6-28.0)$ & 515 & $37(31.1-42.0)$ & 4,749 & $27(26.0-28.4)$ \\
\hline Support services & 6,750 & $28(27.0-28.9)$ & 685 & $37(33.1-41.7)$ & 7,435 & $29(27.5-29.4)$ \\
\hline Laborers & 5,643 & $33(31.8-34.4)$ & 345 & $35(29.6-40.7)$ & 5,988 & $33(32.0-34.6)$ \\
\hline \multicolumn{7}{|l|}{ Industry } \\
\hline Manufacturing/construction & 10,628 & $30(29.9-31.1)$ & 594 & $31(28.6-34.2)$ & 11,222 & $30(29.9-31.0)$ \\
\hline Retail & 3,763 & $29(28.3-30.3)$ & 244 & $32(27.7-36.0)$ & 4,007 & $29(28.4-30.3)$ \\
\hline Finances/information & 2,940 & $26(24.7-26.5)$ & 272 & $38(32.0-43.9)$ & 3,212 & $26(25.2-27.0)$ \\
\hline Profess/admin/man & 3,116 & $26(25.2-27.5)$ & 331 & $30(25.5-35.3)$ & 3,447 & $26(25.4-27.6)$ \\
\hline Education & 2,814 & $23(21.9-23.7)$ & 246 & $29(24.7-34.2)$ & 3,060 & $23(22.1-23.9)$ \\
\hline Health care & 4,201 & $29(27.8-29.8)$ & 426 & $37(33.0-40.7)$ & 4,627 & $29(28.3-30.1)$ \\
\hline Accommodation and food & 2,043 & $33(31.5-35.3)$ & 185 & $28(22.7-32.8)$ & 2,228 & $33(30.9-34.6)$ \\
\hline Public administration, arts & 3,849 & $27(26.4-28.3)$ & 309 & $34(31.1-37.5)$ & 4,158 & $28(26.7-28.6)$ \\
\hline
\end{tabular}


Table 1 Age-adjusted prevalence of short sleep duration by sociodemographic, health behavior and clinical characteristics among 125,610 US Asian and White participants, 2004-2011 (Continued)

\begin{tabular}{|c|c|c|c|c|c|c|}
\hline \multicolumn{7}{|l|}{ Health behaviors } \\
\hline \multicolumn{7}{|l|}{ Smoking status } \\
\hline Never & 15,572 & $26(25.2-26.2)$ & 1,855 & $32(30.4-34.3)$ & 17,427 & $26(25.6-26.5)$ \\
\hline Current & 8,433 & $28(27.2-28.5)$ & 395 & $33(30.0-36.6)$ & 8,828 & $28(27.4-28.6)$ \\
\hline Former & 9,317 & $34(33.3-34.9)$ & 354 & $34(28.8-38.4)$ & 9,671 & $34(33.3-34.8)$ \\
\hline \multicolumn{7}{|l|}{ Alcohol consumption } \\
\hline Never & 3,799 & $27(25.8-27.8)$ & 739 & $31(28.2-33.6)$ & 4,538 & $27(26.2-28.0)$ \\
\hline Current & 19,289 & $27(26.7-27.6)$ & 1,142 & $34(31.9-36.9)$ & 20,431 & $27(26.8-27.8)$ \\
\hline Former & 4,878 & $32(31.2-33.0)$ & 236 & $38(33.0-43.2)$ & 5,114 & $32(31.3-33.2)$ \\
\hline \multicolumn{7}{|c|}{ Leisure-time physical activity } \\
\hline Never/unable & 11,542 & $31(30.8-32.1)$ & 868 & $33(31.1-35.6)$ & 12,410 & $31(30.8-32.1)$ \\
\hline Low & 10,778 & $27(26.0-27.2)$ & 925 & $33(29.9-35.7)$ & 11,703 & $27(26.2-27.4)$ \\
\hline High & 10,917 & $27(26.0-27.1)$ & 809 & $32(28.9-34.4)$ & 11,726 & $27(26.2-27.3)$ \\
\hline \multicolumn{7}{|l|}{ Clinical characteristics } \\
\hline Overweight/Obese ${ }^{a}$ & 21,921 & $30(29.4-30.3)$ & 1,688 & 36 (33.1-37.9) & 23,087 & $30(29.5-30.4)$ \\
\hline Obese $^{b}$ & 10,153 & $33(32.0-33.3)$ & 714 & $38(32.4-43.2)$ & 10,457 & $33(32.2-33.5)^{c}$ \\
\hline Hypertension (yes) & 10,901 & $32(31.1-32.4)$ & 704 & 37 (34.0-40.6) & 11,605 & $32(31.3-32.6)$ \\
\hline Diabetes (yes) & 2,892 & $33(31.8-34.7)$ & 217 & $33(28.0-38.3)$ & 3,109 & $33(31.8-34.6)$ \\
\hline Heart disease (yes) & 4,469 & $33(31.6-33.7)$ & 186 & $42(35.8-48.9)$ & 4,655 & $33(31.8-33.9)$ \\
\hline Cancer (yes) & 3,467 & $31(29.4-31.9)$ & 94 & $30(23.5-37.2)$ & 3,561 & $31(29.4-31.9)$ \\
\hline \multicolumn{7}{|l|}{ Health status } \\
\hline Excellent/very good & 18,680 & $25(24.4-25.2)$ & 1,531 & 31 (28.9-33.1) & 20,211 & $25(24.6-25.4)$ \\
\hline Good & 9,203 & $31(30.5-31.9)$ & 781 & $34(31.3-36.5)$ & 9,984 & $31(30.6-31.9)$ \\
\hline Fair/poor & 5,453 & $40(38.8-40.9)$ & 293 & $42(37.3-47.3)$ & 5,746 & $40(38.9-40.9)$ \\
\hline \multicolumn{7}{|l|}{ Region of country } \\
\hline Northeast & 6,204 & $30(28.9-30.6)$ & 472 & $33(29.4-36.4)$ & 6,676 & $30(29.1-30.7)$ \\
\hline Midwest & 9,823 & $28(27.7-29.3)$ & 352 & 34 (29.0-38.6) & 10,175 & $29(27.7-29.3)$ \\
\hline South & 11,234 & $28(27.8-29.0)$ & 488 & $32(27.9-35.7)$ & 11,722 & $28(27.8-29.1)$ \\
\hline West & 6,093 & $25(24.7-26.2)$ & 1,295 & $32(30.3-34.6)$ & 7,388 & $26(25.5-26.9)$ \\
\hline
\end{tabular}

Weighted estimates; $\mathrm{n}(\%)$.

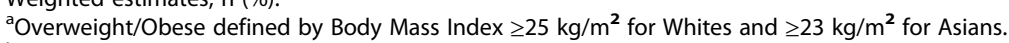

${ }^{b}$ Obesity defined by Body Mass Index $\geq 30 \mathrm{~kg} / \mathrm{m}^{2}$ for Whites and $\geq 27.5 \mathrm{~kg} / \mathrm{m}^{2}$ for Asians.

${ }^{\mathrm{C}}$ Race-specific BMI standards were applied.

${ }^{*}$ Asian subgroups: Chinese (short sleep prevalence $(p)=23.6 \%$ [95\% Cl: $\left.21.0-26.4\right]$ ), Asian Indians ( $p=23.6 \%$ [95\% Cl: 21.0-26.4]), Filipinos ( $p=37.4 \%$ [95\% Cl:

34.7-40.1]) and Other Asians ( $p=33.1 \%$ [95\% Cl: 31.0-35.2]).

employment among Asians and Whites for each year from 2004 to 2011. Although all trends were statistically insignificant, there appeared to be important variation in short sleep by industry for both Asians and Whites. For instance, there was an apparent decline in short sleep among Asians in the Accommodation and Food Industry that became significantly lower $(\mathrm{p}<0.05)$ than Whites while short sleep remained generally stable in Whites over the study period. Short sleep prevalence estimates overlapped by race over time for the Manufacturing/ Construction industry category. Short sleep was consistently higher in Asians than Whites over time in the
Education and Healthcare industries, and the widest disparity over time was observed in the Finance Industry.

\section{Discussion}

In this nationally representative study of Asians and Whites, we confirmed reports that short sleep duration is high in the US, but for the first time show that Asian Americans had an overall age-adjusted prevalence of short sleep that was higher than Whites. Furthermore, we show that the difference in short sleep prevalence between Asians and Whites varied importantly by both industry and occupation, with the largest gap observed in 
Table 2 Adjusted prevalence ratios of short sleep duration for Asians compared to Whites by industry of employment, National Health Interview Survey, 2004-2011 ( $\mathrm{n}=35,961)$

\begin{tabular}{|c|c|c|c|c|c|}
\hline & $\begin{array}{l}\text { Model 1: } \\
\text { Age }\end{array}$ & $\begin{array}{c}\text { Model 2: } \\
\text { Demographics }\end{array}$ & $\begin{array}{c}\text { Model 3: } \\
\text { Health behaviors }\end{array}$ & $\begin{array}{c}\text { Model 4: } \\
\text { Medical conditions }\end{array}$ & $\begin{array}{l}\text { Model 5: } \\
\text { Occupational characteristics }\end{array}$ \\
\hline \multirow{2}{*}{ Manufacturing/construction } & 1.00 & 1.03 & 1.16 & 1.14 & 1.14 \\
\hline & $(0.92-1.08)$ & $(0.95-1.12)$ & $(1.06-1.28)$ & $(1.04-1.26)$ & $(1.03-1.26)$ \\
\hline \multirow{2}{*}{ Retail } & 1.01 & 1.03 & 1.16 & 1.13 & 1.05 \\
\hline & $(0.88-1.16)$ & $(0.90-1.18)$ & $(0.98-1.36)$ & $(0.97-1.33)$ & $(0.87-1.26)$ \\
\hline \multirow{2}{*}{ Finances/information } & 1.30 & 1.36 & 1.49 & 1.44 & 1.46 \\
\hline & $(1.14-1.48)$ & $(1.19-1.54)$ & $(1.29-1.72)$ & $(1.25-1.65)$ & $(1.26-1.69)$ \\
\hline \multirow{2}{*}{ Profess/admin/man } & 0.97 & 1.01 & 1.16 & 1.14 & 1.18 \\
\hline & $(0.86-1.09)$ & $(0.90-1.14)$ & $(1.02-1.33)$ & $(1.00-1.30)$ & $(1.03-1.36)$ \\
\hline \multirow{2}{*}{ Education } & 1.20 & 1.20 & 1.27 & 1.25 & 1.29 \\
\hline & $(1.04-1.37)$ & $(1.04-1.38)$ & $(1.08-1.49)$ & $(1.06-1.47)$ & $(1.08-1.53)$ \\
\hline \multirow{2}{*}{ Health care and social services } & 1.21 & 1.26 & 1.42 & 1.40 & 1.39 \\
\hline & $(1.10-1.34)$ & $(1.13-1.39)$ & $(1.27-1.60)$ & $(1.25-1.57)$ & $(1.22-1.57)$ \\
\hline \multirow{2}{*}{ Accommodation and food } & 0.82 & 0.80 & 0.95 & 0.94 & 0.81 \\
\hline & $(0.70-0.96)$ & $(0.68-0.94)$ & $(0.79-1.15)$ & $(0.79-1.13)$ & $(0.66-0.99)$ \\
\hline \multirow{2}{*}{ Public administration, arts } & 1.19 & 1.20 & 1.38 & 1.37 & 1.35 \\
\hline & $(1.06-1.34)$ & $(1.07-1.35)$ & $(1.22-1.57)$ & $(1.21-1.56)$ & $(1.17-1.56)$ \\
\hline
\end{tabular}

Model 1 adjusted for age categories.

Model 2 adjusted Model $1+$ sex, marital status, educational attainment

Model 3 adjusted Model $2+$ smoking status, alcohol consumption, physical activity.

Model 4 adjusted Model 3 + health status, body mass index, hypertension, diabetes, heart disease, cancer.

Model 5 adjusted Model 4 + class of occupation, occupation, living in poverty, household income.

the Finance/information industry and among both professional and support services occupations. Our study, in combination with previous investigations, suggests that population patterns of sleep duration are likely influenced by a complex interplay between factors in the social and work environment $[18,38]$. Although a high prevalence of short sleep duration among manufacturing/construction, transportation/warehousing, and public administration workers was found in a prior study, the results of this study were not stratified by race. Racial/ethnic health disparities are likely influenced by occupational environments and stressors in the workplace that may, for example, affect sleep quantity and quality. Therefore, racial/ethnic differences in the work-sleep relationship deserve greater attention.

Prior research identifying risk factors for short sleep have focused on SES or race (confounded by SES) [17,39]. These studies identified that lower SES and Black race are

Table 3 Adjusted prevalence ratios of short sleep duration for Asians compared to Whites by occupation, National Health Interview Survey, 2004-2011 ( $n=35,961)$

\begin{tabular}{|c|c|c|c|c|c|}
\hline & $\begin{array}{c}\text { Model 1: } \\
\text { Age }\end{array}$ & $\begin{array}{c}\text { Model 2: } \\
\text { Demographics }\end{array}$ & $\begin{array}{c}\text { Model 3: } \\
\text { Health behaviors }\end{array}$ & $\begin{array}{c}\text { Model 4: } \\
\text { Medical conditions }\end{array}$ & $\begin{array}{c}\text { Model 5: } \\
\text { Occupational characteristics }\end{array}$ \\
\hline \multirow{2}{*}{ Professional/management } & 1.08 & 1.11 & 1.25 & 1.23 & 1.25 \\
\hline & $(0.99-1.17)$ & $(1.02-1.20)$ & $(1.14-1.37)$ & $(1.13-1.35)$ & $(1.14-1.38)$ \\
\hline \multirow{2}{*}{ Support services } & 1.15 & 1.18 & 1.32 & 1.29 & 1.28 \\
\hline & $(1.08-1.22)$ & $(1.10-1.25)$ & $(1.23-1.42)$ & $(1.20-1.39)$ & $(1.18-1.38)$ \\
\hline \multirow{2}{*}{ Laborers } & 1.01 & 0.99 & 1.12 & 1.11 & 1.07 \\
\hline & $(0.93-1.09)$ & $(0.92-1.07)$ & $(1.03-1.22)$ & $(1.02-1.21)$ & $(0.97-1.18)$ \\
\hline
\end{tabular}

Model 1 adjusted for age categories.

Model 2 adjusted Model $1+$ sex, marital status, educational attainment.

Model 3 adjusted Model $2+$ smoking status, alcohol consumption, physical activity.

Model 4 adjusted Model 3 + health status, body mass index, hypertension, diabetes, heart disease, cancer.

Model 5 adjusted Model 4 + class of occupation, living in poverty, household income. 


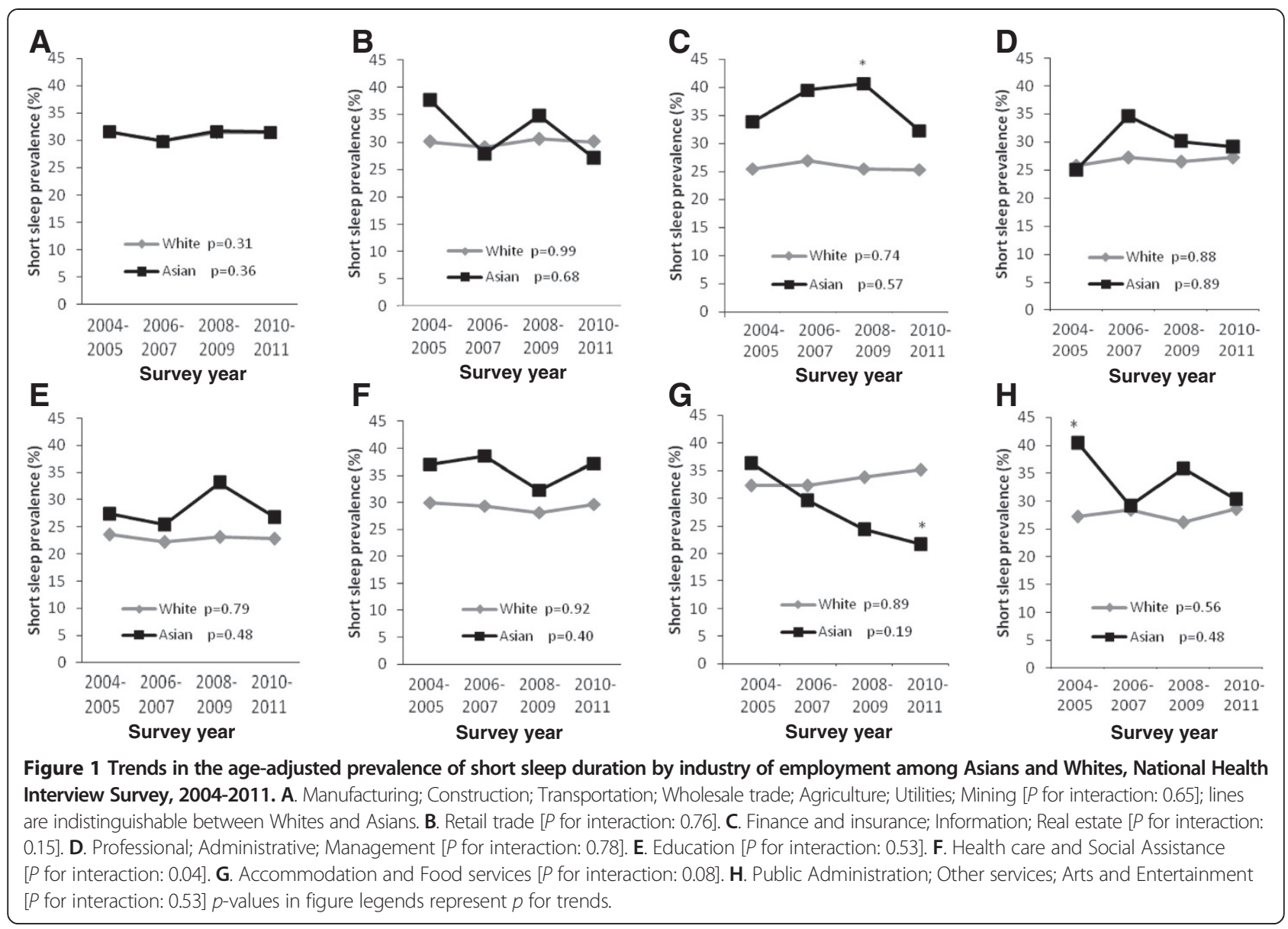

significant risk factors for short sleep, and the relationships were presumed to reflect socioeconomic stressors, including the impact of discrimination on sleep. However, we recently showed that not considering race and SES (e.g. occupation) in combination may limit the inferences from such research. In particular, we recently showed that occupation significantly modified the associations between short sleep and race in a comparison of Blacks and Whites [23]. Similar to the results of that analysis, we now also show that Asian professionals have a higher prevalence of short sleep than White professionals.

Sociocultural factors may connect one's job - a marker of socioeconomic position and potentially large source of psychosocial and environmental stressors - with their overall health as occupational characteristics influence specific sleep conditions. For instance, Asians may experience racial discrimination in the workplace and great pressure to succeed in professional environments, which can conceivably increase stress in ways that displace sleep [40-42]. The work-sleep relationship may also be affected by several factors including voluntary or involuntary extended work hours, rotating or shift work (albeit low in Asians) as well as stress related to the job [19,24,43-45]. A recent study using 2010 data from the National Health Interview Study found that whites (20.9 [20.0-22.0]) were more likely than Asians (16.6 [13.9-19.9]) to formally work at least 48 hours per week [46]. Although non-significant, it appeared that whites (8.1 [7.4-8.8]) were also slightly more likely to work at least 60 hours per week than Asians (5.9 [4.3-8.0]) as well as to engage in alternative shift work (28.1 [27.0-29.2]) for whites vs. 26.2 [22.8-29.8] for Asians). A similar proportion of whites (6.2 [5.6-6.8]) and Asians (6.7 [(5.0-8.8]) worked in temporary positions. Furthermore, technology (e.g. internet with email capabilities, cellular phones) may have also increased the accessibility of employees in ways that enhance job strain as well as disrupt sleep [47,48], and use of technology may have differential impacts by race/ ethnicity. Acculturation and cultural factors (e.g. religious beliefs and practices, strong work ethic) may also be more unique sources of racial/ethnic differences in the worksleep relationship. Additionally, the majority of Asians in this nationally representative sample were non-US born (74\%), and the US born individuals appeared to have the shorter sleep, which is consistent with evidence that Western acculturation negatively influences sleep habits as has been observed among Mexican Americans [49]. As suggested by our subsidiary analysis, it would be useful to further explore sleep differences in those who were born 
in and outside of the US in addition to the impact of certain Asian ethnicities likely being overrepresented in certain occupations, which could spark additional research and ideas for intervention as it is apparent that short sleep may result from social, occupational, and behavioral factors.

The high prevalence of short sleep in Asians raises concerns that this factor may contribute to the risk of diabetes, hypertension, cardiovascular disease and other health problems in this group. Prior research has indicated that Asians report a low frequency of sleep complaints [17]. Unfortunately, there is a profound scarcity of data on sleep architecture and sleep disorders, such as sleep apnea, in Asian Americans [50]. Since some research suggests that short sleep associated with insomnia may have the most adverse effects on health $[51,52]$ it would be important for future studies to further consider the influence of short sleep and sleep disturbances on specific health outcomes among Asian Americans.

Furthermore, since Asians overall tend to possess high SES and other favorable factors that may be protective against suboptimal sleep, there are important opportunities to better understand interactions between sleep duration and SES in studies of health outcomes across racial groups.

Our study has several limitations. For instance, our crosssectional study design precluded our ability to investigate prospective associations between various industries of employment among the employed and sleep duration. We also relied solely on self-reported data. More objective measures of sleep duration than self-report can be obtained through polysomnography and actigraphy [53], but measurements from these technologies were unavailable. To our knowledge, there is also no available validation data on the quality of self-reported (compared to measured) sleep duration among Asian Americans, which presents an important topic for future research. Furthermore, we did not have data on sleep disorders or sleep quality. We also could not account for number of children in the household, which likely influences sleep and differs by race. We also did not have access to data on medication use that may affect sleepiness. Employment status, which can be more variable for lowerSES, minority groups, was based on participants being employed during the week prior to the interview [54]; however, we do not expect for employment status to be more highly variable in Asians compared to Whites. Shift work, shown to differ by race and increase risk of disease, could not be accounted for although we do not expect Asians and Whites to have different participation levels of shift work $[24,55,56]$. Additionally, we did not have enough statistical power to test for differences among the various AsianAmerican groups, despite their known heterogeneity. For instance, Japanese Americans have the highest SES of any group in the US, but Vietnamese have the lowest SES [57].

Nonetheless, our study has important strengths that contribute to the literature. For instance, our data were based on a large population of Asian Americans for which data is typically sparse. We were also able to stratify by multiple factors (e.g. race/ethnicity, industry) while providing stable, robust estimates. Furthermore, we had access to 8 successive years of sleep data, enhancing our power to investigate sleep disparities and trends. These data are also nationally representative and were recently collected. Lastly, prevalence ratios were directly estimated, which makes it easier to interpret the results compared to odds ratios.

\section{Conclusion}

Asian-White differences in short sleep duration varied importantly by industry of employment and occupation, and these complex differences reflect the need to identify as well as understand sociocultural factors that may influence the work-sleep relationship in hopes of effectively addressing the identified sleep disparities for optimal health and productivity among workers in the US.

\section{Additional files}

Additional file 1: Table S1. Sociodemographic, Health Behavior, and Clinical Characteristics among NHIS Participants with Short Sleep Duration by Race/ethnicity, 2004-2011 ( $N=35,961)$.

Additional file 2: Table 2. Adjusted Prevalence Ratios of Short Sleep Duration for Asians Compared to Whites Born in the US $(n=114,177)$ and not $(n=11,380)$ by Industry of Employment, National Health Interview Survey, 2004-2011.

\section{Competing interests}

Authors have no conflicts of interest to disclose.

\section{Authors' contributions}

$\mathrm{CLJ}, \mathrm{IK}, \mathrm{SR}$ and FBH study concept and design. CLJ acquisition of data. CLJ statistical analysis. CLJ, IK, SR and FBH interpretation of data. CLJ drafting of the manuscript. CLJ, IK, SR, HSJ and FBH critical revision of the manuscript for important intellectual content. IK and FBH administrative, technical, and material support. IK and FBH obtaining funding and study supervision. All authors read and approved the final manuscript.

\section{Acknowledgements}

Drs. Hu, Redline and Jackson were supported by Transdisciplinary Research on Energetics and Cancer (TREC) (1U54CA155626-01). The funding sources were not involved in the data collection, data analysis, manuscript writing and publication. The authors have no conflicts of interest to report.

\section{Author details}

${ }^{1}$ Department of Nutrition, Building II, Room 302, Harvard School of Public Health, 655 Huntington Avenue, Boston, MA, USA. ${ }^{2}$ Department of Social and Behavioral Sciences, Harvard School of Public Health, Boston, MA, USA. ${ }^{3}$ Department of Medicine, Brigham and Women's Hospital and Beth Israel Deaconess Medical Center, Harvard Medical School, Boston, MA, USA. ${ }^{4}$ Department of Health, Behavior \& Society, The Johns Hopkins Bloomberg School of Public Health, Baltimore, MD, USA.

Received: 7 December 2013 Accepted: 28 May 2014 Published: 3 June 2014

\section{References}

1. Buxton OM, Marcelli E: Short and long sleep are positively associated with obesity, diabetes, hypertension, and cardiovascular disease among adults in the United States. Soc Sci Med 2010, 71(5):1027-1036. 
2. Hammond EC: Some preliminary findings on physical complaints from a prospective study of 1,064,004 Men and women. Am J Public Health Nations Health 1964, 54:11-23.

3. Gangwisch JE, Heymsfield SB, Boden-Albala B, Buijs RM, Kreier F, Opler MG, Pickering TG, Rundle AG, Zammit GK, Malaspina D: Sleep duration associated with mortality in elderly, but not middle-aged, adults in a large US sample. Sleep 2008, 31(8):1087-1096

4. Gangwisch JE, Heymsfield SB, Boden-Albala B, Buijs RM, Kreier F, Pickering TG, Rundle AG, Zammit GK, Malaspina D: Sleep duration as a risk factor for diabetes incidence in a large U.S. sample. Sleep 2007, 30(12):1667-1673.

5. Gottlieb DJ, Punjabi NM, Newman AB, Resnick HE, Redline S, Baldwin CM, Nieto FJ: Association of sleep time with diabetes mellitus and impaired glucose tolerance. Arch Intern Med 2005, 165(8):863-867.

6. Gottlieb DJ, Redline S, Nieto FJ, Baldwin CM, Newman AB, Resnick HE, Punjabi NM: Association of usual sleep duration with hypertension: the Sleep Heart Health Study. Sleep 2006, 29(8):1009-1014

7. Alvarez GG, Ayas NT: The impact of daily sleep duration on health: a review of the literature. Prog Cardiovasc Nurs 2004, 19(2):56-59.

8. Ayas NT, White DP, Al-Delaimy WK, Manson JE, Stampfer MJ, Speizer FE, Patel S, Hu FB: A prospective study of self-reported sleep duration and incident diabetes in women. Diabetes Care 2003, 26(2):380-384.

9. Steptoe A, Peacey V, Wardle J: Sleep duration and health in young adults. Arch Intern Med 2006, 166(16):1689-1692.

10. Taheri S, Lin L, Austin D, Young T, Mignot E: Short sleep duration is associated with reduced leptin, elevated ghrelin, and increased body mass index. PLoS Med 2004, 1(3):e62.

11. Grandner MA, Hale L, Moore M, Patel NP: Mortality associated with short sleep duration: the evidence, the possible mechanisms, and the future. Sleep Med Rev 2010, 14(3):191-203.

12. Liu R, Zee PC, Chervin RD, Arguelles LM, Birne J, Zhang S, Christoffel KK, Brickman WJ, Zimmerman D, Wang B, Wang G, Xu X, Wang X: Short sleep duration is associated with insulin resistance independent of adiposity in Chinese adult twins. Sleep Med 2011, 12(9):914-919.

13. Yea $\mathrm{H}$ : Relation between sleep quality and quantity, quality of life, and risk of developing diabetes in healthy workers in Japan: the High-risk and Population Strategy for Occupational Health Promotion (HIPOP-OHP) Study. BMC Public Health 2007, 7(1):129.

14. Beckles GL, Zhu J, Moonesinghe R: Diabetes - United States, 2004 and 2008. MMWR Surveill Summ 2011, 60(Suppl):90-93.

15. Li KK, Powell NB, Kushida C, Riley RW, Adornato B, Guilleminault C: A comparison of Asian and white patients with obstructive sleep apnea syndrome. Laryngoscope 1999, 109(12):1937-1940.

16. Cappuccio FP, D'Elia L, Strazzullo P, Miller MA: Sleep duration and all-cause mortality: a systematic review and meta-analysis of prospective studies. Sleep 2010, 33(5):585-592.

17. Grandner MA, Patel NP, Gehrman PR, Xie D, Sha D, Weaver T, Gooneratne N: Who gets the best sleep? Ethnic and socioeconomic factors related to sleep complaints. Sleep Med 2010, 11(5):470-478.

18. Luckhaupt SE, Tak S, Calvert GM: The prevalence of short sleep duration by industry and occupation in the National Health Interview Survey. Sleep 2010, 33(2):149-159.

19. Kuhn P, Lozano F: The expanding workweek? understanding trends in long work hours among U.S. Men, 1979-2006. J Labor Econ 2008, 26(2):311-343.

20. Karasek RA, Theorell T: Healthy work: stress, productivity, and the reconstruction of working life. New York, New York: Basic books, Inc; 1992

21. Krieger N, Waterman PD, Hartman C, Bates LM, Stoddard AM, Quinn MM Sorensen G, Barbeau EM: Social hazards on the job: workplace abuse, sexual harassment, and racial discrimination-a study of Black, Latino, and White low-income women and men workers in the United States. Int J Health Serv 2006, 36(1):51-85.

22. Grandner MA, Hale L, Jackson N, Patel NP, Gooneratne NS, Troxel WM: Perceived racial discrimination as an independent predictor of sleep disturbance and daytime fatigue. Behav Sleep Med 2012, 10(4):235-249.

23. Jackson $\mathrm{CL}$, Redline $\mathrm{S}$, Kawachi I, Williams MA, Hu FB: Racial disparities in short sleep duration by occupation and industry. Am J Epidemiol 2013, 178(9):1442-1451.

24. Pilcher JJ, Lambert BJ, Huffcutt Al: Differential effects of permanent and rotating shifts on self-report sleep length: a meta-analytic review. Sleep 2000, 23(2):155-163.

25. Presser H: Race-ethnic and gender differences in nonstandard work shifts. Work Occup 2003, 30:412-439.
26. Tomfohr L, Pung MA, Edwards KM, Dimsdale JE: Racial differences in sleep architecture: the role of ethnic discrimination. Biol Psychol 2012, 89(1):34-38

27. Hughes D, Dodge MA: African American women in the workplace: relationships between job conditions, racial bias at work, and perceived job quality. Am J Community Psychol 1997, 25(5):581-599.

28. James SA: John Henryism and the health of African-Americans. Cult Med Psychiatry 1994, 18(2):163-182.

29. National Center for Health Statistics, Centers for Disease Control and Prevention. National Health Interview Survey. Hyattsville, MD. Available at: http://www.cdc.gov/nchs/nhis.htm. Accessed November, 2013.

30. Voss $U$, Tuin I: Integration of immigrants into a new culture is related to poor sleep quality. Health Qual Life Outcomes 2008, 6:61.

31. Jackson CL, Redline S, Kawachi I, Hu FB: Association between sleep duration and diabetes in black and white adults. Diabetes Care 2013 36(11):3557-3565.

32. Wang J, Thornton JC, Russell M, Burastero S, Heymsfield S, Pierson RN Jr: Asians have lower body mass index (BMI) but higher percent body fat than do whites: comparisons of anthropometric measurements. Am J Clin Nutr 1994, 60(1):23-28.

33. Minnesota Population Center and State Health Access Data Assistance Center, Integrated Health Interview Series: Version 3.0. 2010, Minneapolis: University of Minnesota.

34. Wolters KM: Introduction to variance estimation. New York, NY: Springer-Verlag: 1990

35. Rao JN, Scott AJ: A simple method for the analysis of clustered binary data. Biometrics 1992, 48(2):577-585.

36. Stata Corp: Stata TX, 2007. 2008. Statistical Software: Released 10. College Station: Stata Corporation; 2010.

37. Barros AJ, Hirakata VN: Alternatives for logistic regression in crosssectional studies: an empirical comparison of models that directly estimate the prevalence ratio. BMC Med Res Methodol 2003, 3:21.

38. Adler NE, Newman K: Socioeconomic disparities in health: pathways and policies. Health Aff (Millwood) 2002, 21(2):60-76.

39. Patel NP, Grandner MA, Xie D, Branas CC, Gooneratne N: "Sleep disparity" in the population: poor sleep quality is strongly associated with poverty and ethnicity. BMC Public Health 2010, 10:475.

40. Bhattacharya G, Schoppelrey SL: Preimmigration beliefs of life success, postimmigration experiences, and acculturative stress: South Asian immigrants in the United States. J Immigr Health 2004, 6(2):83-92.

41. Liang CT, Fassinger RE: The role of collective self-esteem for Asian Americans experiencing racism-related stress: a test of moderator and mediator hypotheses. Cultur Divers Ethnic Minor Psychol 2008, 14(1):19-28.

42. Osajima K: Asian Americans as the model minority: an analysis of the popular press image in the 1960s and. Companion Asian Am Stud 1980, 2005:215-225.

43. Tucker $\mathrm{P}$, Smith $\mathrm{L}$, Macdonald I, Folkard S: The impact of early and late shift changeovers on sleep, health, and well-being in 8- and 12-hour shift systems. J Occup Health Psychol 1998, 3(3):265-275.

44. Ota A, Masue T, Yasuda N, Tsutsumi A, Mino Y, Ohara H: Association between psychosocial job characteristics and insomnia: an investigation using two relevant job stress models-the demand-control-support (DCS) model and the effort-reward imbalance (ERI) model. Sleep Med 2005, 6(4):353-358

45. Ruggiero JS, Redeker NS: Effects of napping on sleepiness and sleep-related performance deficits in night-shift workers: a systematic review. Biol Res Nurs 2014, 16(2):134-142. Epub 2013 Feb 13.

46. Alterman T, Luckhaupt SE, Dahlhamer JM, Ward BW, Calvert GM: Prevalence rates of work organization characteristics among workers in the U.S.: data from the 2010 National Health Interview Survey. Am J Ind Med 2013, 56(6):647-659

47. Costa G: The 24-hour society between myth and reality. J Hum Ergol 2001 30(1-2):15-20

48. Presser HB: Towards a 24-hour economy. Science 1999, 284:1777-1779.

49. Seicean S, Neuhauser D, Strohl K, Redline S: An exploration of differences in sleep characteristics between Mexico-born US immigrants and other Americans to address the Hispanic Paradox. Sleep 2011, 34(8):1021-1031.

50. Mirrakhimov AE, Sooronbaev T, Mirrakhimov EM: Prevalence of obstructive sleep apnea in Asian adults: a systematic review of the literature. BMC Pulm Med 2013, 13:10.

51. Vgontzas AN, Liao D, Pejovic S, Calhoun S, Karataraki M, Bixler EO: Insomnia with objective short sleep duration is associated with type 2 diabetes: a population-based study. Diabetes Care 2009, 32(11):1980-1985. 
52. Fernandez-Mendoza J, Vgontzas AN, Liao D, Shaffer ML, Vela-Bueno A, Basta M, Bixler EO: Insomnia with objective short sleep duration and incident hypertension: the Penn State Cohort. Hypertension 2012, 60(4):929-935.

53. Lauderdale DS, Knutson KL, Yan LL, Liu K, Rathouz PJ: Self-reported and measured sleep duration: how similar are they? Epidemiology 2008, 19(6):838-845.

54. Muntaner C, Hadden WC, Kravets N: Social class, race/ethnicity and all-cause mortality in the US: longitudinal results from the 1986-1994 National Health Interview Survey. Eur J Epidemiol 2004, 19(8):777-784.

55. Ohayon MM, Smolensky MH, Roth T: Consequences of shiftworking on sleep duration, sleepiness, and sleep attacks. Chronobiol Int 2010 27(3):575-589.

56. Ertel KA, Berkman LF, Buxton OM: Socioeconomic status, occupational characteristics, and sleep duration in African/Caribbean immigrants and US White health care workers. Sleep 2011, 34(4):509-518.

57. Frisbie WP, Cho Y, Hummer RA: Immigration and the health of Asian and Pacific Islander adults in the United States. Am J Epidemiol 2001, 153(4):372-380.

doi:10.1186/1471-2458-14-552

Cite this article as: Jackson et al.: Asian-White disparities in short sleep duration by industry of employment and occupation in the US: a cross-sectional study. BMC Public Health 2014 14:552

\section{Submit your next manuscript to BioMed Central and take full advantage of:}

- Convenient online submission

- Thorough peer review

- No space constraints or color figure charges

- Immediate publication on acceptance

- Inclusion in PubMed, CAS, Scopus and Google Scholar

- Research which is freely available for redistribution 